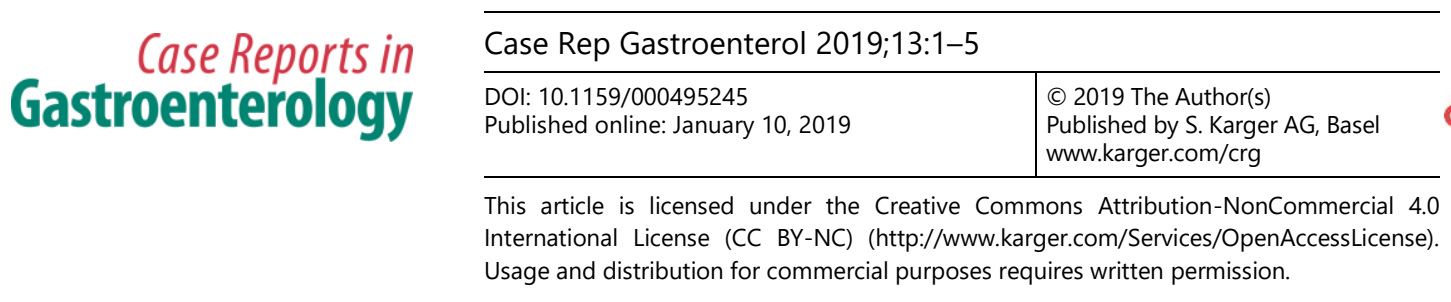

\title{
Successful Endoscopic Management of Double latrogenic Perforations Induced by Endoscopic Retrograde Cholangiopancreatography and Computed Tomography-Guided Colon Drainage
}

\author{
Ping-Hsiu Wu Jui-Hao Chen Kuang-En Chu \\ Division of Hepatology and Gastroenterology, Departments of Internal Medicine, Shin \\ Kong Wu Ho-Su Memorial Hospital, Taipei, Taiwan
}

\section{Keywords}

Endoscopic retrograde cholangiopancreatography · Perforation · Computed tomography-guided drainage

\begin{abstract}
Endoscopic retrograde cholangiopancreatography (ERCP) is a high-risk procedure with a significantly high rate of complications, such as pancreatitis, bleeding, perforation, and infection. Pancreatitis is the most common post-ERCP complication with an incidence of approximately $3.5 \%$. Although perforation is a rare complication with an incidence of $0.1-0.6 \%$, it may be associated with a high rate of mortality of $1.0-1.5 \%$. Here, we report a rare case of ERCP-induced double iatrogenic perforations in the duodenum and colon complicated by an intraabdominal abscess. The post-ERCP perforation was successfully sealed using fibrin glue (Tisseel). The intra-abdominal abscess was treated with a computed tomography-guided pigtail drainage; however, the pigtail spontaneously migrated and perforated the ascending colon. The pigtail was removed, and closure of the colon perforation was successfully achieved with endoscopic clipping. Tisseel spray can be a treatment option for post-ERCP perforations.
\end{abstract}




\section{Case Reports in Gastroenterology}

Case Rep Gastroenterol 2019;13:1-5 DOI: $10.1159 / 000495245$

(c) 2019 The Author(s). Published by S. Karger AG, Basel www.karger.com/crg

Wu et al: Successful Endoscopic Management of Double latrogenic Perforations Induced by Endoscopic Retrograde Cholangiopancreatography

Careful consideration of procedural complications, early detection of perforations, and prompt treatment can be life-saving.

\section{Introduction}

Perforation is a serious complication after all endoscopic interventions. Iatrogenic gastrointestinal perforations have an incidence of $0.03-0.8 \%$ in the routine endoscopic procedures [1]. Notably, if the perforation is recognized immediately during the procedure and treated accordingly without delay, the success rate of endoscopic closure of the defect is generally high. Endoscopic retrograde cholangiopancreatography (ERCP) is an invaluable procedure for pancreaticobiliary diseases not only in diagnosis but also in treatment and is an important complementary tool to imaging techniques, such as magnetic resonance cholangiopancreatography or endoscopic ultrasound. Although post-endoscopic sphincterotomy-related perforation is an uncommon complication after procedures performed by skillful endoscopists, it is an extremely serious condition. Currently, endoscopists use various new and advanced devices for a nonsurgical approach in the management of perforations. A fully covered metal stent may seal the perforation by diverting the biliary content. Endoscopic clipping is also frequently used to close the perforation. Fibrin sealant (Tisseel; Baxter Healthcare, Deerfield, IL, USA) might be an alternative for the occlusion of perforations and has been frequently used to accelerate the closure of colorectal fistulae [2]. For infected or symptomatic fluid collections in the abdominal cavity, computed tomography (CT) enables a more appropriate visualization of the surrounding structures than ultrasound. The success rate of CT-guided percutaneous drainage is over $90 \%$, and the associated complications are quite rare [3]. The most frequently encountered complications are related to sedatives use, contrast media allergy, infection, bleeding, blind and nontargeted access, and accidental pigtail dislodgement. We herein report a rare case of ERCP-induced double iatrogenic perforations in the duodenum and colon complicated by an intra-abdominal abscess, which was successfully managed by endoscopic treatment without further surgical intervention. Catheter obstruction or malposition due to a prolonged use may require further catheter irrigation or exchange.

\section{Case Report}

A 63-year-old woman presented to the emergency department because of intermittent fever $\left(37.5-38^{\circ} \mathrm{C}\right)$, epigastric pain, and dyspepsia for 1 month. Pain may be related to food intake, sometimes radiated to the back, and was relived after assuming a bending position. She had no remarkable medical history except for a laparoscopic cholecystectomy due to gallbladder stones in an outlying hospital 6 months prior to the current admission and an endoscopic sphincterotomy via ERCP just 1 month prior at the same institution due to recurrent common bile duct stones. Intermittent fever and abdominal pain developed shortly after the ERCP, for which she was administered oral antibiotics (cefaclor $500 \mathrm{mg}$ t.i.d.) and painkillers (Ibuprofen $400 \mathrm{mg}$ b.i.d.) after discharge from the previous hospital. However, poor appetite, general weakness, low-grade fever $\left(37.5-38^{\circ} \mathrm{C}\right)$, and epigastric pain persisted despite medical treatment, following which she was referred to the emergency department for a second consultation. Upon admission, her vital signs were stable with an arterial blood pressure of $126 / 83 \mathrm{~mm} \mathrm{Hg}$, heart rate of 91 beats/min, respiratory rate of 18 beats/min, and oxygen saturation of $99 \%$ on room air. Physical examination showed an abdominal tenderness with flank 


\section{Case Reports in Gastroenterology}

Case Rep Gastroenterol 2019;13:1-5 DOI: $10.1159 / 000495245$

(c) 2019 The Author(s). Published by S. Karger AG, Basel www.karger.com/crg

Wu et al. Successful Endoscopic Management of Double latrogenic Perforations Induced by Endoscopic Retrograde Cholangiopancreatography

rebounding pain over the right upper quadrant area. An abdominal ultrasound demonstrated a small amount of ascites in Morrison's pouch, highly suggestive of a retroperitoneal abscess. Laboratory data showed a leukocyte count of $13,800 / \mathrm{mm}^{3}$ (normal range: $3.5-11 \times 10^{3} / \mathrm{mm}^{3}$ ) with $67.6 \%$ of segmented neutrophils, hemoglobin level of $8.2 \mathrm{~g} / \mathrm{dL}$ (normal range: 12-16 $\mathrm{g} / \mathrm{dL}$ ), and platelet count of 760,000/mL (normal range: $150-400 \times 10^{3} / \mathrm{mm}^{3}$ ). Other laboratory findings included blood urea nitrogen $7 \mathrm{mg} / \mathrm{dL}$ (normal range: $6-21 \mathrm{mg} / \mathrm{dL}$ ), serum creatinine $0.95 \mathrm{mg} / \mathrm{dL}$ (normal range: $0.8-1.3 \mathrm{mg} / \mathrm{dL}$ ), sodium $137 \mathrm{mEq} / \mathrm{L}$ (normal range: 135$145 \mathrm{mEq} / \mathrm{L}$ ), potassium $4.0 \mathrm{mEq} / \mathrm{L}$ (normal range: $4.1-5.6 \mathrm{mEq} / \mathrm{L}$ ), serum glutamic oxaloacetic transaminase $16 \mathrm{U} / \mathrm{L}$ (normal range: 8-40 U/L), albumin $2.89 \mathrm{~g} / \mathrm{dL}$ (normal range: 4-5.5 $\mathrm{g} / \mathrm{dL}$ ), total bilirubin $0.54 \mathrm{mg} / \mathrm{dL}$ (normal range: $0.5-1.3 \mathrm{mg} / \mathrm{dL}$ ), lipase $21 \mathrm{U} / \mathrm{L}$ (normal range: $<84 \mathrm{U} / \mathrm{L}$ ), and C-reactive protein $18.4 \mathrm{mg} / \mathrm{dL}$ (normal range: $<1 \mathrm{mg} / \mathrm{dL}$ ).

Abdominal CT showed a periampullary duodenal perforation, a widespread retroperitoneal abscess complicated by a right obstructive uropathy, and possible pseudocyst formation in the mesenteric root. The lower portion of the common bile duct showed narrowing with mild upstream ductal dilatation. The coexistence of a cholangitis was also suspected.

ERCP performed 2 days later detected a large peri-ampullary diverticulum and a copious amount of purulent material coming out from the peri-ampullary perforation (Fig. 1a). First, a double pigtail plastic stent $(7 \mathrm{Fr}, 5 \mathrm{~cm}$ ) was inserted into the bile duct, and concomitantly a single pigtail ( $5 \mathrm{Fr}, 4 \mathrm{~cm}$ ) was inserted into the main pancreatic duct. Fibrin sealant (Tisseel) (Fig. 1b) was then injected to occlude the perforation. A total of $4 \mathrm{~mL}$ of the fibrin sealant was applied around the perforation site. On the same day, under CT guidance, a 7-Fr pigtail was inserted into the right pararenal space to drain the retroperitoneal abscess (Fig. 2a). The procedure was carried out smoothly, and the CT scan obtained immediately after the procedure showed no complications. CT performed on the following day revealed a correctly positioned pigtail (Fig. 2b). However, persistent right lower quadrant pain and high fever recurred on the fourth day after the drainage; therefore, the CT scan was repeated (Fig. 3a); this CT scan revealed migration of the pigtail catheter from the right pararenal space into the ascending colon. Colonoscopy (Fig. 3b) showed a pigtail catheter tip in the lumen of the ascending colon. The catheter was removed, and 4 clips were applied immediately in the defect for closure. Total parenteral nutrition and broad-spectrum antibiotics were administered. The patient's fever subsided gradually, and her general health condition showed satisfactory improvement. The patient was finally discharged.

\section{Discussion}

We describe a rare case of double iatrogenic perforations in the duodenum and colon complicated by an intra-abdominal abscess, which was successfully managed by endoscopic treatment without further surgical intervention. Various endoscopic techniques have been used for closing gastrointestinal perforation, including the use of endoclips, endoloops, and the over-the-scope clip system [4]. Stapfer et al. [5] classified iatrogenic duodenal perforations into 4 categories. Type 1 injury is the perforation of the medial or lateral wall of the duodenum, with severe outcomes and usually requiring surgical intervention. Type 2 injury is the perivaterian perforation usually related to endoscopic sphincterotomy. Type 3 injury is the perforation of the biliary tree during guidewire or basket instrumentation. Type 4 injury is presence of retroperitoneal air alone due to a micro-perforation. Types 2 and 3 or type 4 injuries may be managed by a conservative approach. 


\section{Case Reports in Gastroenterology}

Case Rep Gastroenterol 2019;13:1-5 DOI: $10.1159 / 000495245$

(c) 2019 www.karger.com/crg

Wu et al.: Successful Endoscopic Management of Double latrogenic Perforations Induced by Endoscopic Retrograde Cholangiopancreatography

Tisseel (fibrin sealant) [6] is a 2-component material consisting of fibrinogen and thrombin, with human factor XIII, aprotinin, polysorbate 80 , and calcium chloride. When mixed together, it can form a cell-free clot that can block the perforation. However, only a few cases in the literature have reported the use of Tisseel through an endoscopic approach [7].

Currently, percutaneous image-guided drainage is the first-line treatment for infected or symptomatic fluid collections in the abdomen and pelvis. Surgical drainage is performed only after failure of percutaneous drainage. CT-guided abscess drainage is the modality of choice because it increases accuracy, reduces procedural time, has a high success rate [8], and is a well-accepted treatment modality. Complications can arise as a secondary infection, bleeding into the abscess cavity, inadvertent catheter misplacement, and rupture of the abscess with spillage into the peritoneal cavity [9]. In our case, the initial CT scan showed the correct position of the pigtail catheter, but pigtail migration to the ascending colon was observed 3 days after drainage. To the best of our knowledge, this is a very rare case of pigtail migration to the colon and colon perforation. In conclusion, we demonstrated the successful endoscopic management of double iatrogenic perforations without further surgical intervention. Tisseel spray can be a treatment option for post-ERCP perforations. Furthermore, careful consideration of procedural complications, early detection of perforations, and prompt treatment are life-saving.

\section{Statement of Ethics}

The authors have no ethical conflicts to disclose.

\section{Disclosure Statement}

The authors declare that there are no conflicts of interest.

\section{References}

1 Schmidt A, Fuchs KH, Caca K, Küllmer A, Meining A. The Endoscopic Treatment of Iatrogenic Gastrointestinal Perforation. Dtsch Arztebl Int. 2016 Feb;113(8):121-8.

2 Lamont JP, Hooker G, Espenschied JR, Lichliter WE, Franko E. Closure of proximal colorectal fistulas using fibrin sealant. Am Surg. 2002 Jul;68(7):615-8.

3 Lorenz J, Thomas JL. Complications of percutaneous fluid drainage. Semin Intervent Radiol. 2006 Jun;23(2):194-204.

4 Buffoli F, Grassia R, Iiritano E, Bianchi G, Dizioli P, Staiano T. Endoscopic "retroperitoneal fatpexy" of a large ERCP-related jejunal perforation by using a new over-the-scope clip device in Billroth II anatomy (with video). Gastrointest Endosc. 2012 May;75(5):1115-7.

5 Stapfer M, Selby RR, Stain SC, Katkhouda N, Parekh D, Jabbour N, et al. Management of duodenal perforation after endoscopic retrograde cholangiopancreatography and sphincterotomy. Ann Surg. 2000 Aug;232(2):191-8.

6 Spotnitz WD. Fibrin sealant: the only approved hemostat, sealant, and adhesive - a laboratory and clinical perspective. ISRN Surg. 2014 Mar;2014:203943.

7 Yang HY, Chen JH. Endoscopic fibrin sealant closure of duodenal perforation after endoscopic retrograde cholangiopancreatography. World J Gastroenterol. 2015 Dec;21(45):12976-80.

8 Abusedera MA, Khalil M, Ali AM, Hassan AE. Percutaneous image-guided aspiration versus catheter drainage of abdominal and pelvic collections. Egypt J Radiol Nucl Med. 2013 Jun;44(2):223-30.

9 Sharma BC, Garg V, Reddy R. Endoscopic management of liver abscess with biliary communication. Dig Dis Sci. 2012 Feb;57(2):524-7. 


\section{Case Reports in Gastroenterology}

\begin{tabular}{l|l}
\hline Case Rep Gastroenterol 2019;13:1-5 \\
\hline DOI: 10.1159/000495245 & $\begin{array}{l}\text { C } 2019 \text { The Author(s). Published by S. Karger AG, Basel } \\
\text { www.karger.com/crg }\end{array}$ \\
\hline
\end{tabular}

Wu et al.: Successful Endoscopic Management of Double latrogenic Perforations Induced by Endoscopic Retrograde Cholangiopancreatography
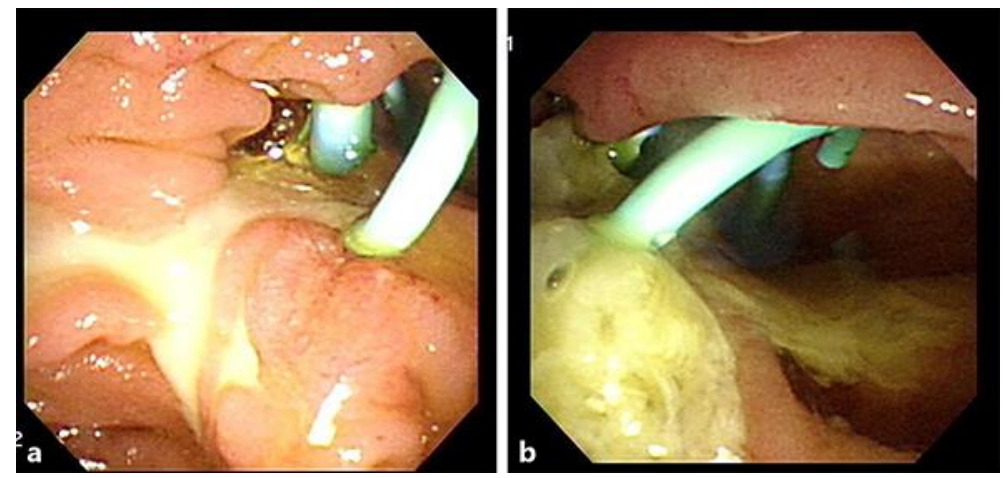

Fig. 1. a Pus coming out from the bile duct after stent insertion. $\mathbf{b}$ Tisseel (4 mL) locally sprayed on the wound.
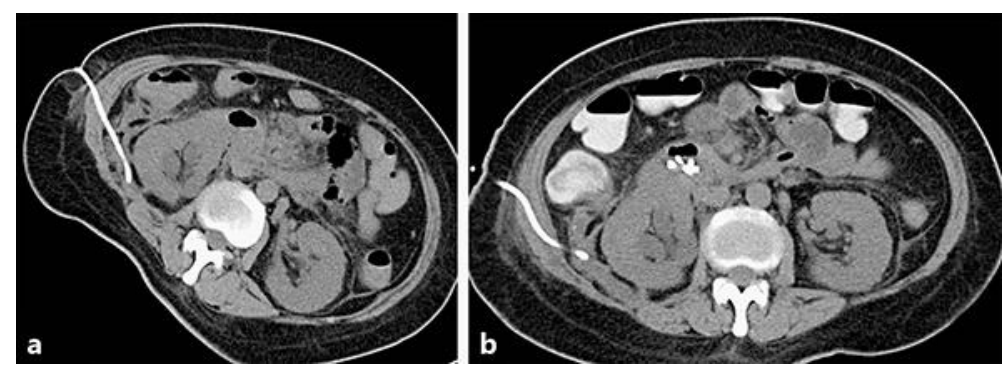

Fig. 2. Computed tomography-guided pigtail insertion to the right pararenal space.
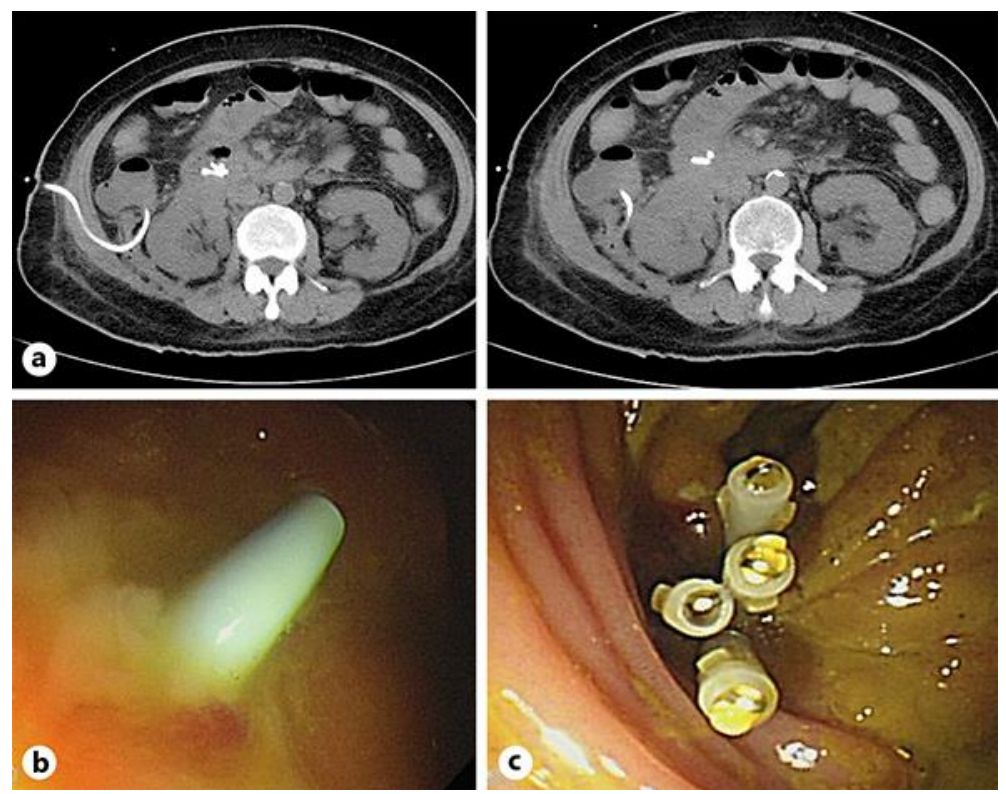

Fig. 3. a Pigtail migration in the ascending colon. b Pigtail in the ascending colon. c Posthemoclipping for closure. 